\title{
A Hybrid Metaheuristic-Deterministic Optimization Strategy for Waste Heat Recovery in Industrial Plants
}

\section{Supporting Information}

\section{Francisco Javier López-Flores, ${ }^{1}$ Luis G. Hernández- Pérez, ${ }^{1}$ Luis Fernando Lira-Barragán, ${ }^{1}$ Eusiel Rubio- Castro $^{2}$ and José María Ponce-Ortega ${ }^{1 *}$}

${ }^{1}$ Chemical Engineering Department, Universidad Michoacana de San Nicolás de Hidalgo, Francisco J. Múgica S/N, Edificio V1, Ciudad Universitaria, 58060, Morelia, Mich., México

${ }^{2}$ Chemical and Biological Sciences Department, Universidad Autónoma de Sinaloa, Av. de las Américas S/N, Culiacán, Sinaloa 80010, México

* Corresponding author: J.M. Ponce-Ortega

E-mail: jose.ponce@umich.mx;

Tel. +52 4433223500 ext. 1277;

Fax. +524433273584

\section{Content (26 pages, 80 equations)}

This supporting information contains equations for the deterministic model as well as data for the case study and tables with results for each thermal engine. It includes sections S1, S2, S3 and S4, Tables S1-S12. 


\section{Supporting Information}

\section{S1. Deterministic Model}

To understand the model, the sets used in the mathematical formulation are defined first. Sets $G$ and $H$ are used for the working fluids available to operate the ORC and the systems available for the AR cycle; the index $g$ represents the organic fluids and $h$ is the system used by the AR cycle. The sets representing hot process streams, cold process streams and internal stages in the superstructure are HPS, CPS and $S T$; the index $i$ is used for the $H P S, j$ denotes $C P S$, and the index $k$ is used for the internal stages of the superstructure. Sets $F, B$, and $T$ denote fossil fuels, biofuels, and time periods (months); indices $f, b$, and $t$ are used to denote fossil fuels, biofuels, and months. The following equations describe the mathematical representation of Figure 4, and it is subdivided into the following sections: first the relationships associated with the HEN model are presented, then the model for the optimal selection of the working fluids, then the model associated with thermodynamic cycles, and finally the objective functions.

\section{Total energy balance for process streams}

The total energy load contained by each $H P S_{i}$ is transferred in the internal stages $k$ to $\operatorname{CPS}_{j}\left(q_{i, j, k}\right), \operatorname{SRC}\left(q_{i, k}^{\text {src }}\right), \operatorname{ORC}\left(q_{i, k}^{\text {orc }}\right)$, and AR cycle $\left(q_{i, k}^{a r 1}\right)$ as in the external stages to cold water $\left(q_{i}^{c w}\right)$ and finally the refrigeration requirements must be met $\left(q_{i}^{a r 2}\right)$.

$$
\left(T_{I N i}-T_{\text {OUTi }}\right) F C p_{i}=\sum_{k \in S T}\left[\begin{array}{l}
\sum_{j \in C P S} q_{i, j, k}+q_{i, k}^{s r c} \\
+q_{i, k}^{o r c 1}+q_{i, k}^{a r 1}
\end{array}\right]+q_{i}^{c w}+q_{i}^{a r 2}, \quad \forall i \in H P S
$$

Similarly, the total heat required by each $C P S_{j}$ is obtained through the exchange of energy with any $H P S_{i}$ and the ORC in all internal stages, as well as the energy received from the SRC:

$$
\left(T_{I N j}-T_{\text {OUTj }}\right) F C p_{j}=\sum_{k \in S T}\left[\sum_{i \in C P S} q_{i, j, k}+q_{j, k}^{o r c 2}\right]+q_{j}^{l p s}, \quad \forall j \in C P S
$$




\section{Energy balance for internal stages}

Furthermore, energy balances are required for internal stages to calculate internal temperatures. Therefore, the following relationships allow calculating the internal temperatures for HPS and CPS:

$$
\begin{aligned}
& \left(t_{i, k}-t_{i, k+1}\right) F C p_{i}=\sum_{j=C P S} q_{i, j, k}+q_{i, k}^{s r c}+q_{i, k}^{o r c 1}+q_{i, k}^{a r 1}, \quad \forall i \in H P S, k \in S T \\
& \left(t_{j, k}-t_{j, k+1}\right) F C p_{j}=\sum_{i=H P S} q_{i, j, k}+q_{j, k}^{o r c 2}, \quad \forall j \in C P S, k \in S T
\end{aligned}
$$

\section{Energy balance for external stages}

The cooling requirements for HPS are achieved through the cold water and AR cycle. These are expressed as follows:

$$
\begin{aligned}
& \left(t_{i, N O K+1}-t_{i}^{a r 2}\right) F C p_{i}=q_{i}^{c w}, \quad \forall i \in H P S \\
& \left(t_{i}^{a r 2}-T_{\text {OUTi }}\right) F C p_{i}=q_{i}^{a r 2}, \quad \forall i \in H P S
\end{aligned}
$$

It should be noted that through the above relationships it is possible to calculate the temperature at the last border of the internal stages $\left(t_{i, N O K+1}\right)$, as well as the temperature prior to the refrigeration $\left(t_{i}^{a r 2}\right)$.

Similarly, for CPS to achieve the target temperatures, it can use heating utility:

$$
\left(T_{\text {OUTj }}-t_{j, 1}\right) F C p_{j}=q_{j}^{l p s}, \quad \forall j \in C P S
$$

\section{Temperature assignment for extreme border of internal stages}

Note that, according to the proposed superstructure, the inlet temperature of each HPS corresponds to the temperature at the first border:

$$
T_{I N i}=t_{i, 1}, \quad \forall i \in H P S
$$

whereas for $C P S$, their inlet temperatures are the same as the temperature at the last boundary of the internal stages:

$$
T_{I N j}=t_{j, N O K+1}, \quad \forall j \in C P S
$$




\section{Constraints for temperature viability in the superstructure}

Since the left side of the superstructure corresponds to the hottest part; while the right side is the coldest area; the temperatures involved in the superstructure must have a monotonic reduction from left to right and the following relationships are needed:

$$
\begin{aligned}
& t_{i, k} \geq t_{i, k+1}, \quad \forall i \in H P S, k \in S T \\
& t_{i, N O K+1} \geq t_{i}^{a r 2}, \quad \forall i \in H P S \\
& t_{i}^{a r 2} \geq T_{\text {OUTi }}, \quad \forall i \in H P S \\
& T_{\text {OUTj }} \geq t_{j, 1}, \quad \forall j \in C P S \\
& t_{j, k} \geq t_{j, k+1}, \quad \forall j \in C P S, k \in S T
\end{aligned}
$$

\section{Existence of heat exchangers}

The mathematical programming model considers a binary variable $(z)$ associated with each heat exchange unit to determine their existence or not (if the unit exists, then $z$ must be equal to one; otherwise, if the exchanger is not required, $z$ equals zero). Therefore, the following logical relationships are included in the formulation, where the existence or not of all heat exchange units is determined as follows:

$$
\begin{aligned}
& q_{i, j, k}-Q_{i, j}^{\max } z_{i, j, k} \leq 0, \quad \forall i \in H P S, j \in C P S, k \in S T \\
& q_{i, k}^{s r c}-Q_{i, k}^{\max } z_{i, k}^{s r c} \leq 0, \quad \forall i \in H P S, k \in S T \\
& q_{i, k}^{\text {orc }}-Q_{i, k}^{\max } z_{i, k}^{\text {orc }} \leq 0, \quad \forall i \in H P S, k \in S T \\
& q_{i, k}^{a r 1}-Q_{i, k}^{\max } z_{i, k}^{a r 1} \leq 0, \quad \forall i \in H P S, k \in S T \\
& q_{i}^{c w}-Q_{i}^{\max } z_{i}^{c w} \leq 0, \quad \forall i \in H P S \\
& q_{i}^{a r 2}-Q_{i}^{\max } z_{i}^{a r 2} \leq 0, \quad \forall i \in H P S \\
& q_{j}^{l p s}-Q_{j}^{\max } z_{j}^{l p s} \leq 0, \quad \forall j \in C P S
\end{aligned}
$$


where $Q_{i, j}^{\max }$ can approximate the highest heat load between the $H P S_{i}$ and $C P S_{j}$, while the total heat load for the $H P S_{i}$ can be used as $Q_{i, k}^{\max }$ and $Q_{i}^{\max }$, finally the total heat load for the $C P S_{j}$ can be used as $Q_{j, k}^{\max }$ and $Q_{j}^{\max }$.

\section{Viability of temperature differences}

In addition to complying with the previous relationships to determine the existence of each heat exchanger unit, all existing units must also satisfy the minimum temperature difference considered for each particular case because this value directly affects the capital costs of the exchanger units. Therefore, if the unit exists, the minimum temperature difference must be met on both sides of each exchanger included in the superstructure; otherwise, if the unit does not exist, an upper limit for the temperature difference is used for each type of exchanger. This is modeled as follows:

$$
\begin{array}{ll}
d t_{i, j, k} \leq t_{i, k}-t_{j, k}+\Delta T_{i, j}^{\max }\left(1-z_{i, j, k}\right), \quad \forall i \in H P S, j \in C P S, k \in S T \\
d t_{i, j, k+1} \leq t_{i, k+1}-t_{j, k+1}+\Delta T_{i, j}^{\max }\left(1-z_{i, j, k}\right), \quad \forall i \in H P S, j \in C P S, k \in S T \\
d t_{i, k}^{s r c} \leq t_{i, k}-T_{O U T}^{s r c}+\Delta T_{i}^{s r c \max }\left(1-z_{i, k}^{s r c}\right), \quad \forall i \in H P S, k \in S T \\
d t_{i, k+1}^{s r c} \leq t_{i, k+1}-T_{I N}^{s r c}+\Delta T_{i}^{s r c \max }\left(1-z_{i, k}^{s r c}\right), \quad \forall i \in H P S, k \in S T \\
d t_{i, k}^{o r c 1} \leq t_{i, k}-T_{O U T}^{o r c 1}+\Delta T_{i}^{o r c 1 \max }\left(1-z_{i, k}^{o r c 1}\right), \quad \forall i \in H P S, k \in S T \\
d t_{i, k+1}^{o r c 1} \leq t_{i, k+1}-T_{I N}^{o r c 1}+\Delta T_{i}^{o r c 1 \max }\left(1-z_{i, k}^{o r c 1}\right), \quad \forall i \in H P S, k \in S T \\
d t_{i, k}^{a r 1} \leq t_{i, k}-T_{O U T}^{a r 1}+\Delta T_{i}^{a r 1 \max }\left(1-z_{i, k}^{a r 1}\right), \quad \forall i \in H P S, k \in S T \\
d t_{i, k+1}^{a r 1} \leq t_{i, k+1}-T_{I N}^{a r 1}+\Delta T_{i}^{a r 1 \max }\left(1-z_{i, k}^{a r 1}\right), \quad \forall i \in H P S, k \in S T \\
d t_{i}^{c w-1} \leq t_{i, N O K+1}-T_{O U T}^{c w}+\Delta T_{i}^{c w \max }\left(1-z_{i}^{c c w}\right), \quad \forall i \in H P S \\
d t_{i}^{c w-2} \leq t_{i}^{a r 2}-T_{I N}^{c w}+\Delta T_{i}^{c w \max }\left(1-z_{i}^{c w}\right), \quad \forall i \in H P S \\
d t_{i}^{a r 2-1} \leq t_{i}^{a r 2}-T_{O U T}^{a r 2}+\Delta T_{i}^{a r 2 \max }\left(1-z_{i}^{a r 2}\right), \quad \forall i \in H P S
\end{array}
$$




$$
\begin{aligned}
& d t_{j, k}^{o r c 2} \leq T_{I N}^{o r c 2}-t_{j, k}+\Delta T_{j}^{o r c 2 \max }\left(1-z_{j, k}^{\text {orc } 2}\right), \quad \forall j \in C P S, k \in S T \\
& d t_{j, k+1}^{\text {orc } 2} \leq T_{\text {OUT }}^{\text {orc } 2}-t_{j, k+1}+\Delta T_{j}^{\text {orc } 2 \max }\left(1-z_{j, k}^{\text {orc } 2}\right), \quad \forall j \in C P S, k \in S T \\
& d t_{j}^{l p s-2} \leq T_{\text {OUT }}^{l p s}-t_{j, 1}+\Delta T_{j}^{l p s \max }\left(1-z_{j}^{l p s}\right), \quad \forall j \in C P S
\end{aligned}
$$

It should be noted that the relationship is not required to include the right side of the $A R 2$ units, nor it is required for the left side of the LPS units, because the temperatures involved in these sides are determined by the solution approach.

Then, it is specified that all the temperature differences; they must be greater than the minimum temperature difference. For this, the following logical constraints are required: $\Delta T_{\min } \leq d t_{i, j, k}, \quad \forall i \in H P S, j \in C P S, k \in S T$

$$
\Delta T_{\min } \leq d t_{i, k}^{s r c}, \quad \forall i \in H P S, k \in S T
$$

$\Delta T_{\min } \leq d t_{i, k}^{o r c 1}, \quad \forall i \in H P S, k \in S T$

$$
\Delta T_{\min } \leq d t_{i, k}^{a r 1}, \quad \forall i \in H P S, k \in S T
$$

$\Delta T_{\min } \leq d t_{i}^{c w-1}, \quad \forall i \in H P S$

$\Delta T_{\min } \leq d t_{i}^{c w-2}, \quad \forall i \in H P S$

$$
\Delta T_{\min } \leq d t_{i}^{a r 2-1}, \quad \forall i \in H P S
$$

$$
\Delta T_{\min } \leq d t_{j, k}^{o r c 2}, \quad \forall j \in C P S, k \in S T
$$

$$
\Delta T_{\min } \leq d t_{j}^{l p s-2}, \quad \forall j \in C P S
$$

\section{Optimal selection of working fluids}

This section addresses the selection of the optimal working fluid to operate the ORC from a set of available working fluids, as well as a disjunctive model to determine the optimal system to run the AR cycle. Here, it is important to note that in each optimal solution, it is 
determined whether the ORC is required or not; while the AR cycle is always necessary because the proposed methodology considers the existence of refrigeration requirements.

\section{Optimal selection of working fluid for ORC}

The following disjunctive model states that, if the ORC is required, it will generate a value for energy production higher than zero. In addition, there is a set of working fluids available for using in the ORC; thus, when the ORC exists, the optimal working fluid must be selected to execute it. In this sense, each working fluid has a characteristic value for the efficiency factor, as well as specific operating temperatures in each step of the ORC. Then, considering these variations between the available working fluids, the disjunctive model will select the optimal working fluid. Finally, the scenario is considered where the ORC does not exist, and all the parameters mentioned above are zero. The above is mathematically represented by the following disjunction:

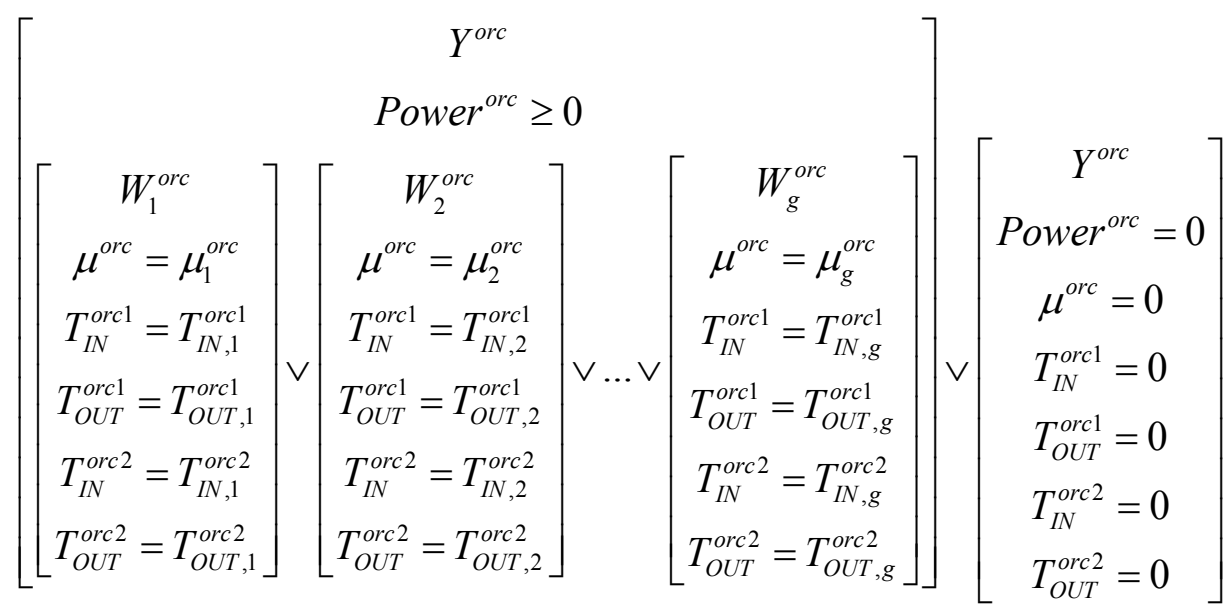

In previous disjunction, $Y^{\text {orc }}$ is a Boolean variable associated with the existence of the ORC, Power ${ }^{\text {orc }}$ represents the amount of energy produced by the ORC, $W_{g}^{\text {orc }}$ is the Boolean variable associated with the selection of the working fluid $g$, the efficiency factor achieved by the organic fluid $g$ is represented by $\mu_{g}^{\text {orc }}$, the input and output temperatures for the ORC1 units are $T_{I N, g}^{o r c 1}$ and $T_{O U T, g}^{o r c 1}$, respectively; finally, $T_{I N, g}^{\text {orc } 2}$ and $T_{O U T, g}^{o r c 2}$ represent the inlet and outlet temperatures for the $O R C 2$ units, respectively.

On the other hand, previous disjunction is transformed into a set of algebraic relationships through the convex Hull technique. ${ }^{\mathrm{S} 1}$ In this sense, each Boolean variable is 
associated with a binary variable to carry out the appropriate reformulation. Therefore, when the Boolean variable is true, the associated binary variable is set to one; otherwise, if the Boolean variable is false, the binary variable must be set to zero. Then, the following logical relationship states that when the ORC is required, a working fluid must be selected; otherwise, if the ORC is not required, no working fluid is activated:

$$
y^{o r c}=\sum_{g \in G} w_{g}^{o r c}
$$

The following relationship states that, if the ORC exists, the amount of electricity produced must be less than an upper limit ( Power $\left.^{\text {orc_Max }}\right)$ :

$$
\text { Power }^{\text {orc }} \leq \text { Power }_{\text {orc }}^{\text {oax }} y^{\text {orc }}
$$

Furthermore, the chosen efficiency factor is obtained through the following relationship:

$\mu^{o r c}=\sum_{g \in G} \mu_{g}^{o r c} w_{g}^{o r c}$

It should be noted that only one working fluid can be selected (equation S45). Regarding the selection of the four temperatures involved in the ORC, the same type of mathematical relationships are used:

$$
\begin{aligned}
& T_{I N}^{\text {orc } 1}=\sum_{g \in G} T_{I N, g}^{o r c 1} w_{g}^{\text {orc }} \\
& T_{\text {OUT }}^{\text {orc } 1}=\sum_{g \in G} T_{\text {OUT }, g}^{\text {orc } 1} w_{g}^{\text {orc }} \\
& T_{I N}^{\text {orc } 2}=\sum_{g \in G} T_{I N, g}^{\text {orc } 2} w_{g}^{\text {orc }} \\
& T_{\text {OUT }}^{\text {orc } 2}=\sum_{g \in G} T_{\text {OUT }, g}^{\text {orc } 2} w_{g}^{\text {orc }}
\end{aligned}
$$

Moreover, the following relationships state that if the ORC is required, then heat exchange between the ORC with HPS and CPS may be possible; in the other case, if the ORC does not exist, then the possibility of heat exchange with ORC is eliminated: 


$$
\begin{aligned}
& y^{\text {orc }} \geq z_{i, k}^{\text {orc } 1}, \quad \forall i \in H P S, k \in S T \\
& y^{\text {orc }} \geq z_{j, k}^{\text {orc } 2}, \quad \forall j \in C P S, k \in S T
\end{aligned}
$$

\section{Optimal system selection for AR cycle}

This work considers the optimal selection of the system to operate the AR cycle (there can only be one AR cycle in the optimal solution). To carry out this task, the following disjunctive model is used (where $Y_{h}^{a r}$ represents the Boolean variable associated with the selection of system $h$ to run system AR):

$$
\left[\begin{array}{c}
Y_{1}^{a r} \\
C O P^{a r}=C O P_{1}^{a r} \\
T_{I N}^{a r 2}=T_{I N, 1}^{a r 2} \\
T_{O U T}^{a r 2}=T_{O U T, 1}^{a r 2}
\end{array}\right] \vee\left[\begin{array}{c}
Y_{2}^{a r} \\
C O P^{a r}=C O P_{2}^{a r} \\
T_{I N}^{a r 2}=T_{I N, 2}^{a r 2} \\
T_{O U T}^{a r 2}=T_{O U T, 2}^{a r 2}
\end{array}\right] \vee \ldots \vee\left[\begin{array}{c}
Y_{h}^{a r} \\
C O P^{a r}=C O P_{h}^{a r} \\
T_{I N}^{a r 2}=T_{I N, h}^{a r 2} \\
T_{O U T}^{a r 2}=T_{O U T, h}^{a r 2}
\end{array}\right]
$$

The above disjunction is used to select the optimal system from a set of available systems. Each available system has a characteristic value for $C O P_{h}^{a r}$, and depending on the system, change the values of the inlet and outlet temperatures for the $A R 2$ units $\left(T_{I N, h}^{a r 2}\right.$ and $T_{O U T, h}^{a r 2}$, respectively). It should be noted that the above temperatures drastically affect the lowest temperature that HPS can achieve.

When the above disjunctive model is reformulated into a set of algebraic equations, it obtains the following logical relationships. First, a system must be chosen:

$$
\sum_{h \in H} y_{h}^{a r}=1
$$

Then, the COP, inlet and outlet temperatures for AR cycle operation are selected according to the selected system:

$$
\begin{aligned}
& \operatorname{COP}^{a r}=\sum_{h \in H} \operatorname{COP}_{h}^{a r} y_{h}^{a r} \\
& T_{I N}^{a r 2}=\sum_{h \in H} T_{I N, h}^{a r 2} y_{h}^{a r}
\end{aligned}
$$


$T_{\text {OUT }}^{a r 2}=\sum_{h \in H} T_{\text {OUT,h }}^{a r 2} y_{h}^{a r}$

\section{Thermodynamic cycles and their interactions}

To model the operation of the AR cycle, a COP is considered, whereas the modeling for thermodynamic cycles is performed through efficiency factors $(\mu)$. In addition, this section states that the heat available in the condenser in the SRC (wasted heat) can be used in the ORC cycle, AR and in the HEN.

\section{Modeling for the SRC}

The energy balance for all external energy sources supplied to the boiler placed in the $\mathrm{SRC}$ is indicated as follows:

$Q^{\text {External }}=Q_{t}^{\text {Solar }}+\sum_{b \in B} Q_{b, t}^{\text {Biofuel }}+\sum_{f \in F} Q_{f, t}^{\text {Fossil }}, \quad \forall t \in T$

where $Q^{\text {External }}$ represents the total energy provided to the SRC.

The power produced by the SRC is equal to the total energy fed to the cycle multiplied by an efficiency factor that represents the thermal efficiency to convert the external energy supplied to the cycle into electricity.

Power $^{\text {src }}=Q^{\text {External }} \mu^{\text {src }}$

Then, the remaining waste heat (heat that cannot be converted into energy) is sent to the ORC (to produce electricity), to the AR system (to produce cooling) and to the HEN (as a heating utility):

$Q^{s r c_{-} m p s}=Q^{o r c_{-} m p s}+Q^{a r_{-} m p s}+\sum_{j \in C P S} q_{j}^{l p s}$

The overall energy balance for the SRC states that the total energy supplied to the cycle $\left(Q^{\text {External }}\right)$ turns into electricity $\left(P o w e r r^{s r c}\right)$ or it can be sent to other subsystems ( $\left.Q^{s r c_{-} m p s}\right)$, as well as the possible heat transfer to the cooling water is also considered $\left(Q^{s r c_{-} c w}\right.$ ): 
$Q^{\text {External }}=$ Power $^{s r c}+Q^{s r c_{-} m p s}+Q^{s r c_{-} c w}$

It should be noted that the worst-case scenario for waste heat is heat transfer with cold water, as this option generates an operating cost (cost of cooling water) and it is not further used for relevant applications.

\section{Modelling for the ORC}

According to the proposed scheme, the ORC can receive heat from the $\mathrm{SRC}$ ( $Q^{\text {orc } \_m p s}$ ), as well as it considers the heat transfer from HPS to ORC $q_{i, k}^{\text {orcl }}$. Then, to determine the power produced by the ORC ( Power $\left.{ }^{\text {orc }}\right)$, it considers the efficiency factor $\left(\mu^{\text {orc }}\right)$ as follows:

$$
\text { Power }^{\text {orc }}=\left(Q^{\text {orc_mps }}+\sum_{i \in H P S} \sum_{k \in S T} q_{i, k}^{\text {orc } 1}\right) \mu^{\text {orc }}
$$

Furthermore, the residual energy (available in the ORC condenser) can be used by the $\operatorname{CPS}\left(q_{j, k}^{\text {orc } 2}\right)$ or can be transferred to cold water $\left(Q^{\text {orc } \_c w}\right)$ :

$$
Q^{\text {orc_mps }}+\sum_{i \in H P S} \sum_{k \in S T} q_{i, k}^{\text {orc1 }}=\text { Power }^{\text {orc }}+\sum_{j \in H P S} \sum_{k \in S T} q_{j, k}^{o r c 2}+Q^{o r c_{-} c w}
$$

It is important to note that the efficiency factor and operating temperatures for the ORC depend on the working fluid selected to run the cycle. In this sense, the value of the operating temperatures is an important factor for the viability of the heat transfer between the $H P S$ and the ORC, as well as for the heat exchange from the ORC to the CPS, which can reduce the use of utilities.

\section{Modelling for the AR}

The balance for the AR system establishes that the cooling load below the ambient temperature required by $\operatorname{HPS}\left(q_{i}^{a r 2}\right)$ must be supplied by excess heat from the $\operatorname{HPS}\left(q_{i, k}^{a r 1}\right)$, as well as by the energy available in the $\operatorname{SRC}$ condenser $\left(Q^{a r_{-} m p s}\right)$. This energy balance also considers a $C O P$ as a factor to describe the energy conversion between the heat provided and the cooling obtained; therefore, the following mathematical relationship is necessary: 
$\frac{\sum_{i \in H P S} q_{i}^{a r 2}}{C O P^{a r}}=\sum_{i \in H P S} \sum_{k \in S T} q_{i, k}^{a r 1}+Q^{a r_{-} m p s}$

\section{Maximum energy production}

Before the optimization process, the desired maximum power generation (i.e., the maximum electricity that will be produced by the SRC and ORC) must be analyzed and determined, which can be obtained through a study considering the project's own electricity requirements and the maximum amount of energy that can be sold to other industries or local governments. This constraint is modeled as follows:

Power $^{\text {src }}+$ Power $^{\text {orc }} \leq$ Power $^{\text {Max }}$

where Power $^{\text {Max }}$ represents the desired maximum power output.

\section{Optimal size for the solar collector and maximum availability for biofuels}

External energy sources are used to provide external energy requirements, such as solar collector, biofuels, and fossil fuels. In this sense, the solar collector may or may not exist in the optimal solution (because it represents the most expensive source of energy; however, at the same time it is the cleanest energy); then, if the solar collector is required, its optimal area must be determined. In addition, an important limitation that must be considered for the use of biofuels is the variation for their production during the year.

\section{Optimal size for the solar collector}

If a solar collector is selected in the optimal solution, its optimal size should be determined by the following relationship. This equation also determines the total solar energy provided to the system $\left(Q_{t}^{\text {Solar }}\right)$. It should be noted that if the total solar energy required in the optimal solution is zero, it means that it is not necessary to install the solar collector:

$$
Q_{t}^{\text {Solar }} \leq Q_{t}^{\text {Useful_Solar }} A_{c}^{\text {Solar }} \frac{1}{D_{t}}, \quad \forall t \in T
$$

where $Q_{t}^{\text {Useful_Solar }}$ represents the useful solar energy for solar radiation available in the specific location where the solar collector can be installed (in this case, this value includes 
the efficiency associated with the equipment), $A_{c}^{\text {Solar }}$ is the optimal area of the solar collector and $D_{t}$ is a conversion factor for changing units of time.

\section{Maximum availability for biofuels}

Given the availability of biofuels, which changes dramatically throughout the year, then the following restriction must be included in the model:

$Q_{b, t}^{\text {Biofuel }} \leq \frac{\text { Heating }_{b}^{\text {Power }} \text { Avail }_{b, t}^{\text {Max }}}{D_{t}}, \quad \forall b \in B, t \in T$

where Heating Power $_{b}$ represents the heating power for biofuel $b$, and $A v a i l_{b, t}^{\text {Max }}$ indicates the maximum amount of biofuel $b$ available in the period $t$.

\section{Objective Functions}

The proposed problem is a multi-objective MINLP problem that simultaneously considers economic, environmental, and social issues (which are important criteria included in sustainability).

Therefore, the economic objective is to maximize the TAP; considering that the environmental objective accounted for in the proposed methodology is the minimization of net $G H G$, and finally the social objective is to maximize the jobs generated by the project:

$$
O F=\left\{\text { Max TAP;Min NGHGE } E^{\text {Overall }} ; \text { Max Jobs }\right\}
$$

The first two objective functions ( Max TAP, Min NGHGE $E^{\text {Overall }}$ ) contradict each other; then the number of jobs the project can create plays an important role for the decision makers and local governments involved in the project.

\section{Economic objective function}

The economic objective function aims to maximize profit, which includes the RSP (Revenues from the selling of power) and $T C R$ (Tax credits reduction), minus the $C a C$ (Capital costs), FiC (fixed cost), $O C$ (operating cost) and ESC (Energy sources cost):

Max profit $=R P S+T C R-C a C-F i C-O C-E S C$ 
These terms are described as follows:

a) Revenues from the selling of power $(R S P)$. The main economic benefits are obtained through the sale of the energy generated by the SRC and the ORC:

$$
R S P=t_{o p} D^{s h}\left(\text { GaPow }^{\text {src }} \text { Power }^{\text {src }}+\text { GaPow }^{\text {orc }} \text { Power }^{\text {orc }}\right)
$$

where $t_{o p}$ denotes the hours of operation hours per year of the plant, $D^{s h}$ is a conversion factor, which transforms seconds to hours, $\mathrm{GaPow}^{\text {src }}$ and $\mathrm{GaPow}^{\text {orc }}$ represent the unit profits from the sale of energy produced in the SRC and ORC, respectively. These unit gains are determined considering the unit price of energy, as well as the energy production costs for the SRC ( PPCost $\left.t^{s r c}\right)$ and ORC (PPCos $\left.t^{\text {orc }}\right)$, respectively,

$$
\begin{aligned}
& \text { GaPow }{ }^{\text {src }}=S P^{e l e c}-P P \operatorname{Cos} t^{\text {src }} \\
& \text { GaPow }{ }^{\text {orc }}=S P^{\text {elec }}-P P \operatorname{Cos} t^{\text {orc }}
\end{aligned}
$$

b) Tax credits reduction $(T C R)$. Recently, several governments have promoted the use of cleaner energy through tax credits. Based on this, the project can obtain tax credits for the use of solar energy, biofuels and even some fossil fuels (because some of them reduce GHG compared to coal):

$$
T C R=t_{o p}\left\{\begin{array}{l}
R^{\text {Solar }}\left[\sum_{t \in T}\left(Q_{t}^{\text {Solar }} D_{t}\right)\right]+\sum_{t \in T} \sum_{b \in B}\left[R_{b}^{\text {Biofuel }} Q_{b, t}^{\text {Biofuel }} D_{t}\right] \\
+\sum_{t \in T} \sum_{f \in F}\left[R_{f}^{\text {Fossil }} Q_{f, t}^{\text {Fossil }} D_{t}\right]
\end{array}\right\}
$$

where $R^{\text {Solar }}, R_{b}^{\text {Biofuel }}$ and $R_{f}^{\text {Fossil }}$ represent unit tax credits for solar energy, biofuels, and fossil fuels, respectively.

c) Capital costs $(\mathrm{CaC})$. The capital costs included are the capital cost for the AR cycle and the capital costs for all the heat exchanger units shown in Figure 4. In this way, the proposed methodology uses the Chen approximation ${ }^{\mathrm{S} 2}$ to avoid logarithmic terms in the optimization model to determine the logarithmic mean temperature difference for the heat exchange units. 


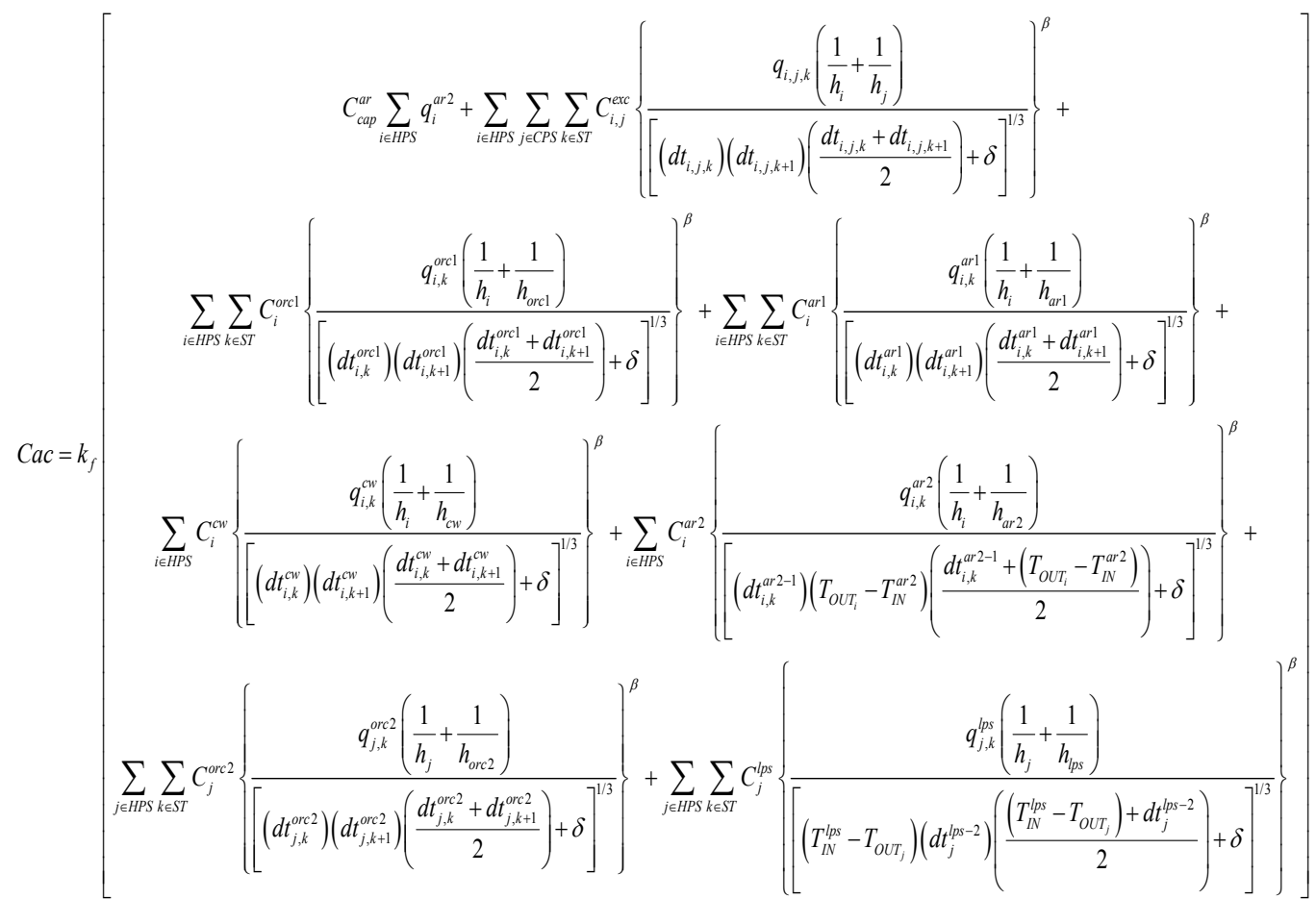

(S73)

d) Fixed costs $(F i C)$. The fixed costs accounted for by this work are the fixed cost for all exchangers required in the optimal solution:

$F i C=k_{f}\left[\begin{array}{l}\sum_{i \in H P S} \sum_{j \in C P S} \sum_{k \in S T} C_{F_{i, j}}^{e x c} z_{i, j, k}+\sum_{i \in H P S} \sum_{k \in S T} C_{F_{i}}^{o r c} z_{i, k}^{o r c 1}+\sum_{i \in H P S} \sum_{k \in S T} C_{F_{i}}^{a r 1} z_{i, k}^{a r 1} \\ +\sum_{i \in H P S} C_{F_{i}}^{c w} z_{i}^{c w}+\sum_{i \in H P S} C_{F_{i}}^{a r 2} z_{i}^{a r 2}+\sum_{j \in C P S} \sum_{k \in S T} C_{F_{j}}^{o r c} z_{j, k}^{o r c 2}+\sum_{j \in C P S} C_{F_{j}}^{l p s} z_{j}^{l p s}\end{array}\right]$

where $C_{F_{i, j}}^{e x c}, C_{F_{i}}^{o r c 1}, C_{F_{i}}^{a r 1}, C_{F_{i}}^{c w}, C_{F_{i}}^{a r 2}, C_{F_{j}}^{o r c 2}$ and $C_{F_{j}}^{l p s}$ represent fixed costs for exchangers, coolers $O R C 1$, coolers $A R 1$, coolers $c w$, coolers $A R 2$, heaters $O R C 2$ and heaters $L P S$, respectively.

e) Operating costs $(O C)$. The considered operating costs are the costs of cooling water for cooling HPS $\left(q_{i}^{c w}\right)$, as well as in the SRC condenser $\left(Q^{s r c}{ }^{c w}\right)$ and the ORC ( $\left.Q^{\text {orc_cw }}\right)$ :

$O C=C_{c w}\left[\sum_{i \in H P S} q_{i}^{c w}+Q^{s r c \_c w}+Q^{o r c \_c w}\right]$ 
f) Energy source costs $(E S C)$. The economic function includes costs related to primary energy sources (fossil fuels, biofuels, and solar collector):

$E S C=t_{o p}\left\{\sum_{f \in F}\left[C_{f}^{\text {Fossil }} \sum_{t \in T}\left(Q_{f, t}^{\text {Fossil }} D_{t}\right)\right]+\sum_{b \in B}\left[C_{b}^{\text {Bioffuel }} \times \sum_{t \in T}\left(Q_{b, t}^{\text {Biofuel }} D_{t}\right)\right]\right\}+t_{o p} C_{o p}^{\text {Solar }}+k_{f} C_{\text {cap }}^{\text {Solar }}$

where $C_{f}^{\text {Fossil }}, C_{b}^{\text {Biofuel }}$ are the unit cost for fossil fuels $f$ and biofuels $b, C_{o p}^{\text {Solar }}, C_{\text {cap }}^{\text {Solar }}$ are capital cost and operating cost for solar collector and they are expressed as follows:

$$
\begin{aligned}
& C_{\text {cap }}^{\text {Solar }}=F C^{\text {Solar }} Z^{\text {Solar }}+V C^{\text {Solar }}\left(A_{c}^{\text {Solar }}\right)^{\alpha^{\text {Solar }}} \\
& C_{\text {op }}^{\text {Solar }}=C u^{\text {Solar }} \sum_{t \in T}\left(Q_{t}^{\text {Solar }} D_{t}\right)
\end{aligned}
$$

where $F C^{\text {Solar }}$ and $V C^{\text {Solar }}$ represent the fixed and variable unit costs for the capital cost of the collector solar, $Z^{\text {Solar }}$ is a binary variable used to model the existence of the solar collector, $\alpha^{\text {Solar }}$ is an exponent of the area to consider the economies of scale in the capital cost function for the solar collector and $\mathrm{Cu}^{\text {Solar }}$ is the unit operating cost.

It should be noted that, depending on the value of the trade-offs between revenues and costs, in some cases the benefit may be positive, while in other cases it may have a negative value.

\section{Environmental objective function}

The environmental impact assessment is carried out through the general quantification of $G H G$ because fossil fuels and biofuels release carbon dioxide when burned:

Min NGHGE $E^{\text {Overall }}=\sum_{t \in T} \sum_{f \in F}\left[G H G E_{f}^{\text {Fossil }} Q_{f, t}^{\text {Fossil }} D_{t}\right]+\sum_{t \in T} \sum_{b \in B}\left[G H G E_{b}^{\text {Biofuel }} Q_{b, t}^{\text {Biofulel }} D_{t}\right]$

where $\operatorname{Min} N G H G E^{\text {Overall }}$ are generally global GHGs released to the environment, while $G H G E_{f}^{\text {Fossil }}$ and $G H G E_{b}^{\text {Biofuel }}$ are the individual $G H G$ for fossil fuels $f$ and biofuels $b$. It is important to note that individual GHGs are determined through life cycle analysis given in units of tonnes of $\mathrm{CO}_{2 e q}$ per $\mathrm{kJ}$ generated. 


\section{Social objective function}

The proposed methodology implies the maximization of the number of jobs that can be created through the implementation of the project. These jobs are generated by the production of fossil fuels, biofuels and by the operation of the solar collector to provide the energy requirements of the project. To quantify the number of jobs created, the JEDI model is used (jobs and economic development impact). In this regard, Miller and Blair ${ }^{\mathrm{S} 3}$ used the JEDI model for economic and social sciences, which is based on an input-output analysis. The input-output analysis is based on the use of multipliers, where a multiplier is a simple ratio of total systemic change over the initial change resulting from a given economic activity. This provides estimates of the total impact resulting from an initial change in economic output (e.g. employment) through the implementation or completion of a project. The size of the multiplier depends on several economic factors, such as the level of local spending for a given industry, the degree of sales outside the local region, the type of industry, and other regional considerations. Based on this, the total effect of a onetime expense can be calculated by adding the three effects, using specific regional multipliers and personal spending patterns. ${ }^{\mathrm{S} 4}$, S5 Therefore, the social function is to maximize the number of jobs created by the project to produce fossil fuels, biofuels and the solar collector:

$\operatorname{Max}_{N J O B S^{\text {Overall }}}=\left(\begin{array}{l}\sum_{t \in T} \sum_{f \in F}\left[N J O B_{f}^{\text {Fossil }} Q_{f, t}^{\text {Fossil }} D_{t}\right]+\sum_{t \in T} \sum_{b \in B}\left[N J O B_{b}^{\text {Biofuel }} Q_{b, t}^{\text {Biofuel }} D_{t}\right]+ \\ \sum_{t \in T}\left[N J O B^{\text {Solar }} Q_{t}^{\text {Solar }} D_{t}\right]\end{array}\right)$

where $N O B_{f}^{\text {Fossil }}, N J O B_{b}^{\text {Biofuel }}$ and $N J O B^{\text {Solar }}$ represent the number of jobs generated by $k J$ provided by fossil fuels, biofuels, and solar collectors, respectively.

\section{S2. Case Study}

In Table S1, six HPS and five CPS are available for energy integration. Also, Table S2 (data for ORC taken from Mago et al. ${ }^{\text {S6) }}$ ) shows three potential working fluids ORC and two AR cycles. Table $\mathbf{S 3}$ shows the maximum availability of biofuels that can be used as a primary energy source. 
Table S1. Stream data for the addressed case study.

\begin{tabular}{llll}
\hline Stream & Inter Temperatura $(\mathrm{K})$ & Outlet Temperature $(\mathrm{K})$ & $\mathrm{FCp}(\mathrm{kW})$ \\
\hline H1 & 345 & 278 & 22.4 \\
H2 & 448 & 342 & 25.84 \\
H3 & 300 & 273 & 77.80 \\
H4 & 288 & 271 & 226.50 \\
H5 & 488 & 383 & 27.85 \\
H6 & 543 & 395 & 9.40 \\
C1 & 358 & 453 & 19.50 \\
C2 & 370 & 418 & 55.30 \\
C3 & 283 & 315 & 135.45 \\
C4 & 278 & 298 & 215.65 \\
C5 & 338 & 416 & 62.15 \\
\hline
\end{tabular}

Table S2. Working fluids and systems available.

\begin{tabular}{|c|c|c|c|c|c|c|c|c|c|c|c|}
\hline \multicolumn{7}{|c|}{ ORC } & \multicolumn{5}{|c|}{ AR cycle } \\
\hline \# & $\begin{array}{l}\text { Working } \\
\text { fluid }\end{array}$ & $\mu_{g}^{\text {orc }}$ & $T_{I N, g}^{O R C 1}(K)$ & $T_{\text {OUT, }}^{\text {ORC1 }}(K)$ & $T_{I N, g}^{O R C 2}(K)$ & $T_{\text {OUT, }}^{\text {ORC2 }}(K)$ & \# & System & COP & $T_{I N, h}^{a r 1}(K)$ & $T_{\text {OUT }, h}^{a r 1}(K)$ \\
\hline 1 & R113 & 0.19 & 294 & 458 & 298 & 295 & 1 & $\mathrm{H} 2 \mathrm{O}-\mathrm{LiBr}$ & 1.2 & 268 & 268 \\
\hline 2 & $\mathrm{R} 245 \mathrm{ca}$ & 0.17 & 305 & 443 & 308 & 306 & 2 & $\mathrm{NH}_{3}-\mathrm{H}_{2} \mathrm{O}$ & 0.7 & 243 & 243 \\
\hline 3 & Isobutene & 0.145 & 304 & 398 & 306 & 305 & - & - & - & - & - \\
\hline
\end{tabular}

Table S3. Monthly amount available for the biofuels (kg/month).

\begin{tabular}{lllllllllllll}
\hline Fuel/month & Jan & Feb & Mar & Apr & May & Jun & Jul & Aug & Sep & Oct & Nov & Dec \\
\hline Biomass & 50,000 & 70,000 & 180,000 & 320,000 & 450,000 & 600,000 & 700,000 & 600,000 & 500,000 & 350,000 & 120,000 & 60,000 \\
Biogas & 25,000 & 35,000 & 50,000 & 42,000 & 40,000 & 45,000 & 45,000 & 39,000 & 49,000 & 58,000 & 32,000 & 27,000 \\
Softwood & 35,000 & 40,000 & 60,000 & 100,000 & 130,000 & 120,000 & 120,000 & 85,000 & 70,000 & 50,000 & 38,000 & 32,000 \\
Hardwood & 33,000 & 41,000 & 75,000 & 90,000 & 120,000 & 125,000 & 125,000 & 80,000 & 70,000 & 45,000 & 40,000 & 33,000 \\
\hline
\end{tabular}

The required parameters are presented as follows:

- An electrical production of up to $10 \mathrm{MW}$.

- Tax credit of $\$ 5 /$ tonCO $\mathrm{C}_{2}$ eq.

- The hours of operating by year are $8760 \mathrm{~h} /$ year.

- Factor used to annualize the capital costs $k_{f}$ is 0.1 year $^{-1}$.

- The fixed capital cost and variable for the solar collector are $\$ 75,526.61$ and $\$ 40.78 / \mathrm{m}^{2}$, while that unit operating cost is $\$ 0.012 / \mathrm{kWh}$, and finally $\alpha^{\text {Solar }}$ is 1 .

- The unit cost of the cooling water $C_{c w}$ is of $\$ 20 /($ year $\mathrm{kW})$. 
- The unit number of job positions generated by the solar collector is $9,95459 \times 10^{-10}$ Jobs/ kJ.

- The minimum temperature difference $\Delta T_{\min }$ is $10 \mathrm{~K}$.

Furthermore, Table S4 presents the useful energy that the solar collector can capture monthly (parabolic trough solar collector-PTSC). Whereas Table S5 presents the fossil fuels and biofuels considered, as well as the values of the parameters associated with them. Figures S1-S3 represent the implementation of the thermal engines in Aspen Plus, these were simulated and optimized based on the parameters presented in this case study.

Table S4. Useful collected energy per month for the solar collector.

\begin{tabular}{ll}
\hline $\begin{array}{l}\text { Month/type of solar } \\
\text { collector }\end{array}$ & $\begin{array}{l}\text { PTSC }\left[\mathrm{kJ} /\left(\mathrm{m}^{2}\right.\right. \\
\text { month })]\end{array}$ \\
\hline January & 409,293 \\
February & 443,016 \\
March & 577,530 \\
April & 571,860 \\
May & 555,768 \\
June & 454,410 \\
July & 443,610 \\
August & 439,425 \\
September & 394,470 \\
October & 410,470 \\
November & 407,430 \\
December & 522,288 \\
\hline
\end{tabular}

Table S5. Data for the fossil fuels and biofuels considered in the examples presented.

\begin{tabular}{lllll}
\hline Fuels & $\begin{array}{l}\text { Heating Power } \\
(\mathrm{kJ} / \mathrm{kg})\end{array}$ & $\begin{array}{l}\text { Overall GHGE } \\
\text { (ton CO2eq } / \mathrm{kJ})\end{array}$ & $\begin{array}{l}\text { Cost } \\
(\$ / \mathrm{mm} \mathrm{kJ})\end{array}$ & $\begin{array}{l}\text { Generation of } \\
\text { jobs }(\mathrm{Jobs} / \mathrm{kJ})\end{array}$ \\
\hline Fossil fuels & & & & \\
1. Coal & 35,000 & $2.21357 \times 10^{-7}$ & 1.5559 & $1.06281 \times 10^{-11}$ \\
2. Oil & 42,200 & $8.05408 \times 10^{-8}$ & 18.2447 & $1.81677 \times 10^{-11}$ \\
3. Natural gas & 54,000 & $7.90892 \times 10^{-8}$ & 5.8349 & $5.25431 \times 10^{-11}$ \\
Biofuels & & & & \\
1. Biomass & 17,200 & $2.44307 \times 10^{-8}$ & 2.0303 & $6.6964 \times 10^{-8}$ \\
2. Biogas & 52,000 & $2.68216 \times 10^{-8}$ & 8.5388 & $5.25431 \times 10^{-7}$ \\
3. Softwood & 20,400 & $3.3482 \times 10^{-8}$ & 2.5332 & $1.46691 \times 10^{-8}$ \\
4. Hardwood & 18,400 & $3.3482 \times 10^{-8}$ & 2.8975 & $5.43641 \times 10^{-8}$ \\
\hline
\end{tabular}




\section{S3. Figures}

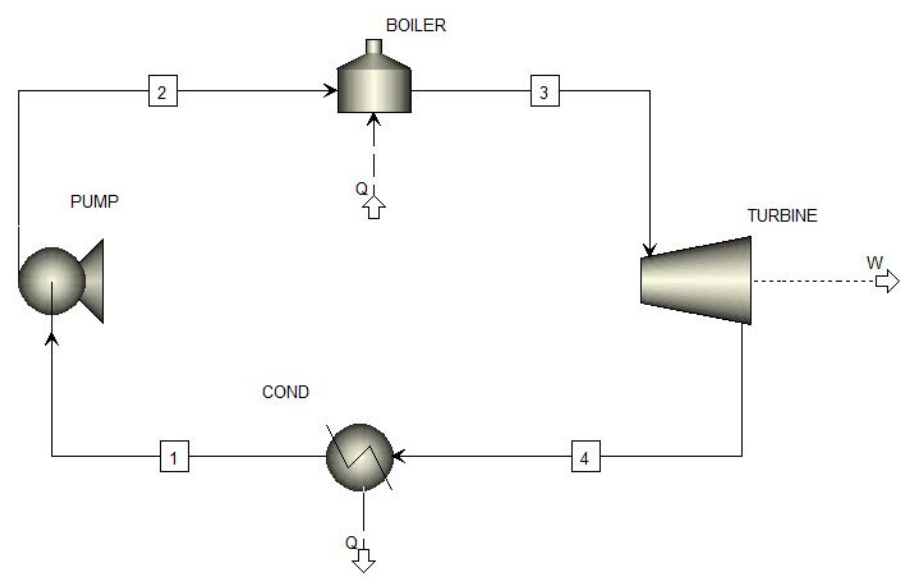

Figure S1. Steam Rankine Cycle (SRC) in Aspen plus ${ }^{\circledR}$.

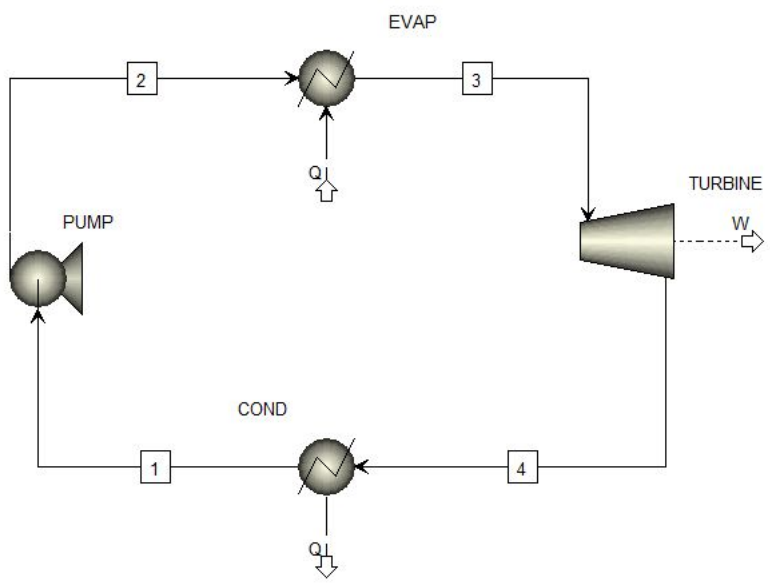

Figure S2. Organic Rankine Cycle (ORC) in Aspen plus ${ }^{\circledR}$. 


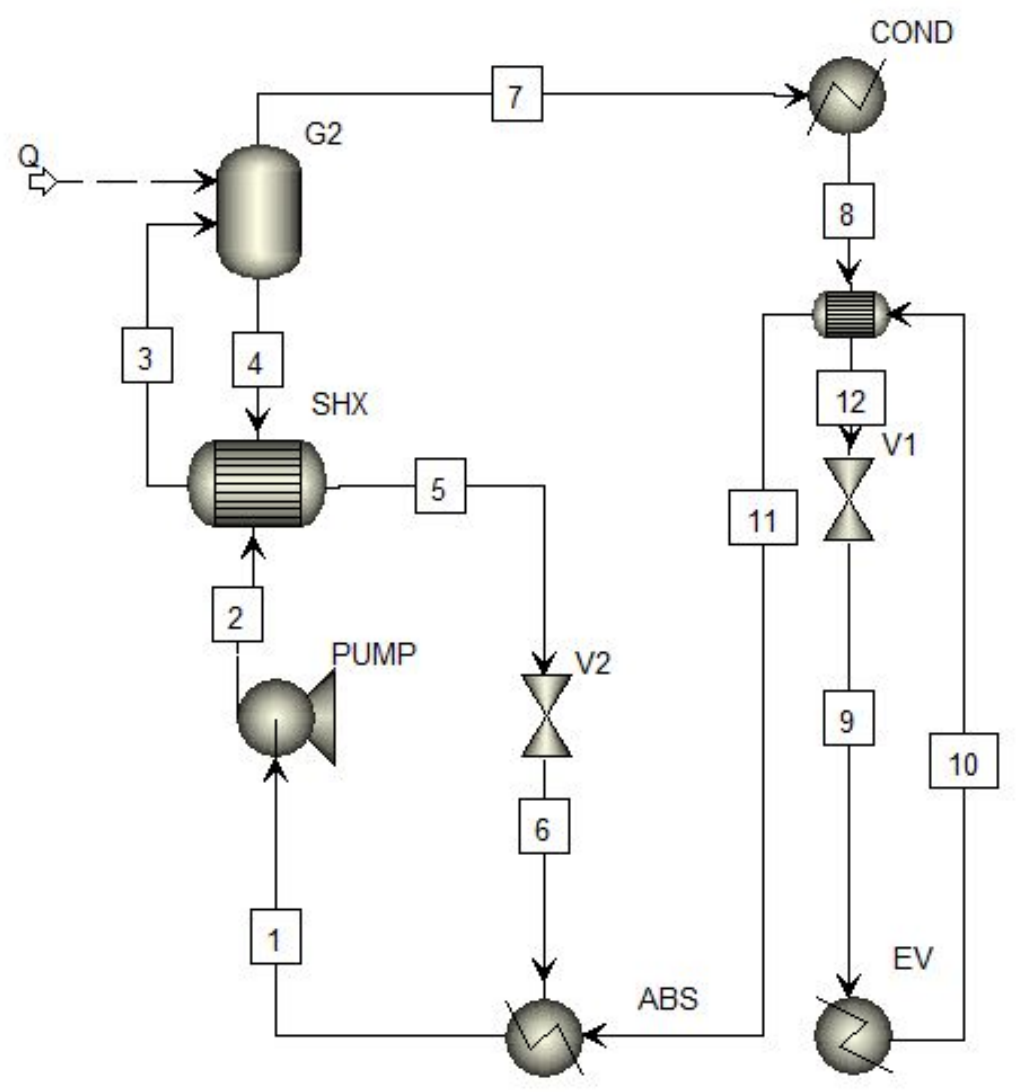

Figure S3. Absorption refrigeration (AR) cycle in Aspen-Plus ${ }^{\circledR}$.

\section{S4. Tables}

Table S6. AR Cycle calculation sequence.

\begin{tabular}{ll}
\hline Stages & Assumption \\
\hline 1 & Saturated Liquid \\
2 & Determined by the solution pump model \\
3 & Determined by the SHX model \\
4 and 7 & Saturated liquid, Saturated vapor; the mass flow \\
& rate ratio between states 4 and 7 is determined by the \\
& temperature of the waste heat available. \\
5 & Determined by the SHX model \\
6 & Determined by the solution valve 2 model \\
8 & Determined by the condenser model (Saturated liquid) \\
9 & Determined by the refrigerant valve 1 model \\
10 & Determined by the evaporator model \\
11 and 12 & Determined by the vapor-liquid heat exchanger model \\
\hline
\end{tabular}


Table S7. Initial conditions for the simulation.

\begin{tabular}{ll}
\hline Parameter & Value \\
\hline System SRC & 622 \\
$T_{1}(K)$ & - \\
$T_{2}(K)$ & - \\
$T_{3}(K)$ & 623 \\
$T_{4}(K)$ & 0.28 \\
$\eta_{t}^{\text {src }}$ & 32151.12 \\
$Q_{\text {boiler }}^{\text {src }}(\mathrm{kW})$ & \\
System ORC & $\mathrm{R} 245 \mathrm{CA}$ \\
Working fluid & 306 \\
$T_{1}(K)$ & 305 \\
$T_{2}(K)$ & 443 \\
$T_{3}(K)$ & 308 \\
$T_{4}(K)$ & 0.17 \\
$\eta_{t}^{\text {orc }}$ & $5,868.73$ \\
$Q_{e v}^{\text {orc }}(k W)$ & \\
System AR & $\mathrm{NH}-\mathrm{H}_{2} \mathrm{O}$ \\
Working fluid $_{T_{\text {in }, e v}^{a r}(K)}^{a r}(K)$ & 243 \\
$T_{\text {out }, e v}$ & 243 \\
COP & 0.7 \\
$Q_{g}^{a r}(k W)$ & $10,645.57$ \\
\hline & \\
\hline &
\end{tabular}


Table S8. Input variables to GAMS ${ }^{\circledR}$ determined by metaheuristic optimization.

\begin{tabular}{|c|c|}
\hline GAMS input variables & Symbol \\
\hline Efficiency ORC & $\eta_{\text {orc }}$ \\
\hline Efficiency SRC & $\eta_{s r c}$ \\
\hline Coefficient of performance & $C O P$ \\
\hline Power production unit cost ORC & $P P \operatorname{Cos} t^{o r c}$ \\
\hline Power production unit cost SRC & $P P \operatorname{Cos} t^{s r c}$ \\
\hline Unitary capital cost AR & $C_{c a p}^{a r}$ \\
\hline Temperatures for the SRC & $T_{I N}^{L P S}$ and $T_{O U T}^{L P S}$ \\
\hline Temperatures for the ORC & $T_{I N}^{O R C 1}, T_{\text {OUT }}^{O R C 1}, T_{I N}^{O R C 2}$ and $T_{\text {OUT }}^{O R C 2}$ \\
\hline Temperatures for the AR & $T_{I N}^{a r 1}$ and $T_{O U T}^{a r 1}$ \\
\hline Film coefficient Stream Hot & $h_{i}$ \\
\hline Film coefficient Stream Cold & $h_{j}$ \\
\hline Film coefficient Stream AR1 & $h_{a r 1}$ \\
\hline Film coefficient Stream AR2 & $h_{a r 2}$ \\
\hline Film coefficient Stream ORC1 & $h_{\text {orc } 1}$ \\
\hline Film coefficient Stream ORC2 & $h_{\text {orc } 2}$ \\
\hline Film coefficient Stream LPS & $h_{l p s}$ \\
\hline
\end{tabular}


Table S9. Shell and tube heat exchanger costs (APEA)

\begin{tabular}{lcc}
\hline Streams (hot/cold) & Qexc $_{\text {e }}$ ) & Cost $(\$)$ \\
\hline H1,AR2 & 1500.8 & 13,300 \\
H2,C3 & $2,739.0$ & 12,200 \\
H3,AR2 & $2,100.6$ & 42,600 \\
H4,AR2 & $3,850.5$ & $2,632,900$ \\
H5,ORC1 & $1,328.9$ & 217,400 \\
H5,C3 & $1,595.3$ & 11,400 \\
H6,C5 & $1,391.2$ & 10,500 \\
LPS,C1 & $1,852.5$ & 25,400 \\
LP2,C2 & $2,654.4$ & 24,800 \\
ORC2,C4 & $4,313.0$ & 30,300 \\
LPS,C5 & $3,456.5$ & 25,400 \\
& \multicolumn{2}{c}{ Total cost } \\
\hline
\end{tabular}

Table S10. Best solution data for SRC.

\begin{tabular}{lll}
\hline Variable & Ref $\mathrm{S} 7$ & Last iteration \\
\hline$T_{1}(\mathrm{~K})$ & 622 & 621.0 \\
$T_{2}(\mathrm{~K})$ & - & 666.7 \\
$T_{3}(\mathrm{~K})$ & - & $1,069.2$ \\
$T_{4}(\mathrm{~K})$ & 623 & 769.8 \\
$P_{\text {high }}(\mathrm{atm})$ & - & 755.2 \\
$P_{\text {low }}(\mathrm{atm})$ & - & 158.6 \\
$\dot{m}_{\mathrm{H}_{2} \mathrm{O}}(\mathrm{kg} / \mathrm{s})$ & - & 12.9 \\
$\eta_{t}^{\text {src }}$ & 0.28 & 0.249 \\
\hline
\end{tabular}


Table S11. Best solution data for ORC.

\begin{tabular}{lll}
\hline Variable & Ref $\mathrm{S} 6, \mathrm{~S} 7$ & Last iteration \\
\hline$T_{1}(\mathrm{~K})$ & 306 & 300.6 \\
$T_{2}(K)$ & 305 & 302.2 \\
$T_{3}(K)$ & 443 & 508.6 \\
$T_{4}(K)$ & 308 & 415.8 \\
$P_{\text {high }}(\mathrm{atm})$ & - & 35 \\
$P_{\text {low }}(\mathrm{atm})$ & - & 1.1 \\
$m^{(\mathrm{kg} / \mathrm{s})}$ & - & 18.5 \\
$\eta_{t}^{\text {orc }}$ & 0.17 & 0.203 \\
\hline
\end{tabular}

Table S12. Data for each of the stages of the best solution of the AR cycle.

\begin{tabular}{llllllll}
\hline Stages & From & To & Temperature $(\mathrm{K})$ & Pressure(atm) & Vapor fraction & Mass flow(kg/s) & $\begin{array}{l}\mathrm{NH}_{3}, \\
\text { Concentration (\%) }\end{array}$ \\
\hline 1 & Absorber & Pump & 261 & 1.22 & 0 & 17.5 & 60 \\
2 & Pump & SHX & 261 & 18.3 & 0 & 17.5 & 60 \\
3 & SHX & Generator & 313 & 18.3 & 0 & 17.5 & 60 \\
4 & Generator & SHX & 364 & 18.3 & 0 & 13.2 & 48 \\
5 & SHX & Valve & 298 & 18.3 & 0 & 13.2 & 48 \\
6 & Valve & Absorber & 278 & 1.22 & 0.06 & 13.2 & 48 \\
7 & Generator & Condenser & 364 & 18.3 & 1 & 4.29 & 98 \\
8 & Condenser & Valve & 321 & 18.3 & 0 & 4.29 & 98 \\
9 & Valve & Evaporator & 244 & 1.22 & 0.02 & 4.29 & 98 \\
10 & Evaporator & LVHX & 247 & 1.22 & 0.86 & 4.29 & 98 \\
11 & LVHX & Absorber & 303 & 1.22 & 1 & 4.29 & 98 \\
12 & LVHX & Valve & 250 & 18.3 & 0 & 4.29 & 98 \\
\hline \multicolumn{7}{c}{ COP } & $\mathbf{0 . 5 4}$
\end{tabular}




\section{References}

(S1) Ponce-Ortega, J. M.; Jimenez-Gutierrez, A.; Grossmann I. E. Optimal synthesis of heat exchanger networks involving isothermal process streams. Comput. Chem. Eng. 2008, 32, 1918-1942. DOI:10.1021/ie500301s.

(S2) Chen, C. L.; Lin, C. Y., 2012. Design of entire energy systems for chemical plants. Ind. Eng. Chem. Res. 2012, 51, 9980-9996.DOI:10.1021/ie202716q.

(S3) Miller, R. E.; Blair, P. D. Input-output analysis: foundations and extensions; Cambridge University Press: Cambridge, U.K., 2009.

(S4) Goldberg, M.; Sinclair, K.; Milligan, M. Job and Economic Development Impact (JEDI) Model: A User-Friendly Tool to Calculate Economic Impacts from Wind Projects; NREL/CP-500-35953; National Renewable Energy Laboratory: Golden, CO, 2004.

(S5) You, F.; Tao, L.; Graziano, D. J.; Snyder, S. W. Optimal design of sustainable cellulosic biofuel supply chains: Multiobjective optimization coupled with life cycle assessment and input-output analysis. AIChE J. 2012, 58, 1157-1180. DOI:10.1002/aic.12637.

(S6) Mago, P. J.; Chamra, L. M.; Somayaji, C. Performance analysis of different working fluids for use in organic Rankine cycles. J. Power Energy 2007, 221, 255-64. Doi:10.1016/j.csite.2015.09.003.

(S7) Lira-Barragán, L. F.; Ponce-Ortega, J. M.; Serna-González, M.; El-Halwagi, M. M. Optimal design of process energy systems integrating sustainable considerations. Energy 2014, 76, 139-160. DOI: 10.1016/j.energy.2014.04.111. 